\title{
СИНДРОМЫ, РАЗВИВШИЕСЯ ПРИ НЕОТЛОЖНЫХ СОСТОЯНИЯХ У ДЕТЕЙ РАННЕГО ВОЗРАСТА С ОСТРЫМИ КИШЕЧНЫМИ ИНФЕКЦИЯМИ
}

\author{
${ }^{1}$ Кулиева 3.М., ${ }^{2}$ Рустамова Л.И.* \\ 'Азербайджанский Государственный Институт Усовершенствования врачей им. А.Алиева, кафед- \\ ра педиатрии, Баку, Азербайджан;
}

${ }^{2}$ Научно-Исследовательский Институт Медицинской Профилактики им. В.Ю.Ахундова, отдел вирусологии, Баку, Азербайджан

В настоящей статье проанализированы синдромы, развившиеся при неотложных состояниях у детей раннего возраста с
острыми кишечными инфекциями. 338 детей раннего возраста с неотложными состояниями были обследованы бакте-
риологическими, серологическими и молекулярно-биологическими методами. Установлено, что у обследованных паци-
ентов в $63,0 \%$ случаев отмечался эксикоз, в $21,6 \%$ - судороги, в $15,9 \%$ - сердечно-сосудистая недостаточность, в $15,0 \%-$
дыхательная недостаточность, в $12,1 \%$ - нейротоксикоз и в $6,8 \%$ - инфекционно-токсический шок. По нашим клиниче-
ским наблюдениям у детей раннего возраста нейротоксикоз отмечается особенно при бактериально-вирусной кишечной
инфекции. Результаты исследований показывают, что у детей раннего возраста с неотложными состояниями вышеотме-
ченные синдромы в основном наблюдаются при бактериально-вирусной кишечной инфекции.
Ключевые слова: острая кишечная инфекция, неотложное состояние, бактериально-вирусная кишечная инфекция, дети
раннего возраста.

Актуальность проблемы острых кишечных инфекций (ОКИ) у детей обусловлена сохранением ведущего места в структуре детской заболеваемости и смертности [5, 6, 11].

Диарейные заболевания занимают второе место в структуре смертности от инфекций детей младше 5 лет по всему миру.

По данным экспертов ВО3, среди 1-1,2 млрд. диарейных заболеваний, регистрируемых ежегодно, от 49-67\% приходится на вирусные инфекции, среди которых наиболее значимыми являются ротавирусы и норовирусы $[1,2,4,7,11]$.

При ОКИ у детей могут развиться большинство известных неотложных состояний (не только обезвоживание), вероятность развития которых зависит как от этиологии заболевания, возраста детей и состояния их преморбидного фона, так и от спектра токсинов микроба- возбудителя $[3,8,10]$.

ОКИ характеризуется выраженным местным синдромом (стул «без счета», с большим количеством воды или других патологических примесей - слизи, зелени, гноя, крови), развитием целого ряда тяжелых синдромов (эксикоз II-III степени, гиповолемический шок, первичный токсикоз I-II-III степени, ИТШ I-II-III степени, гемолитико-уремический синдром, острая почечная недостаточность), своевременная диагностика которых очень важна для выбора адекватной тактики в отделениях реанимации и интенсивной терапии $[5,6,9]$.

Тяжесть состояния больных с ОКИ определяется наличием ряда синдромов: кишечным эксикозом II-III степени, нейротоксикоз, дыхательная недостаточность, судорожный синдром, сердечно-сосудистая недостаточность, инфекционно-токсический шок, ДВС синдром, ГУС, ОПН и др., которые приводят к развитию неотложных состояний.

Материалы и методы. Нами были проведены наблюдения за 338 детьми, у которых наблюдались вышеуказанные синдромы, что отражены в нижеследующей таблице. Для обследования пациентов были использованы клинический, бактериологический, серологический и молекулярно-биологический методы.

Результаты и их обсуждение. Как видно из таблицы, наиболее часто из всех синдромов отмечался эксикоз - у 213 (63\%) больных, из них $182(82,44 \%)$ при ОКИ различной этиологии, значительно реже при кишечной инфекции неясной этиологии (КИНЭ) у 31 (14,55\%). Далее в структуре синдромов последующие места занимали судорожный, сердечно сосудистая недостаточность, дыхательная недостаточность, нейротоксикоз, инфекционно-токсический шок. В единичных случаях были определены ДВС синдром, ОПН, ГУС и другие. Тяжесть состояния обуславливалась сочетанием нескольких синдромов.

*e-mail: iris.ax@mail.ru 
Частота основных синдромов у больных с неотложными состояниями при ОКИ

\begin{tabular}{|l|c|c|c|c|c|c|}
\hline \multirow{2}{*}{\multicolumn{1}{c|}{ Синдромы }} & \multicolumn{2}{c|}{$\begin{array}{c}\text { ОКИ } \\
\text { различной } \\
\text { этиологии }\end{array}$} & \multicolumn{2}{c|}{ КИНЭ } & \multicolumn{2}{c|}{ Всего } \\
\cline { 2 - 7 } & абс. & $\%$ & абс. & $\%$ & абс. & $\%$ \\
\hline Эксикоз & 182 & 85,4 & 31 & 14,5 & 213 & 63 \\
\hline Судорожный & 61 & 83,6 & 12 & 25,6 & 73 & 21,6 \\
\hline Сердечно сосудистая недостаточность & 48 & 88,8 & 6 & 11,1 & 54 & 15,9 \\
\hline Дыхательная недостаточность & 49 & 96,0 & 2 & 3,9 & 51 & 15,0 \\
\hline Нейротоксикоз & 39 & 95,1 & 2 & 4,8 & 41 & 12,1 \\
\hline Инфекционно-токсический шок & 21 & 91,3 & 2 & 8,7 & 23 & 6,8 \\
\hline ГУС & 5 & 1,4 & - & - & 5 & 1,4 \\
\hline ОПН & 3 & 0,9 & - & - & 3 & 0,9 \\
\hline ДВС & 2 & 0,6 & - & - & 2 & 0,6 \\
\hline
\end{tabular}

По сравнению с ОКИ различной этиологии заболевания.

частота этих синдромов при КИНЭ была незначительной и отсутствие некоторых из них (ГУС, ОПН, ДВС) по-видимому обусловлено тем, что указанные синдромы у них не успевали развиться так, как эти больные поступали на стационарное лечение в более ранние сроки

Нами было также изучено частота этих же синдромов при ОКИ у детей раннего возраста с неотложными состояниями в зависимости от этиологического фактора - бактериальной, вирусной и бактериально-вирусной, что иллюстрирована на рисунке.

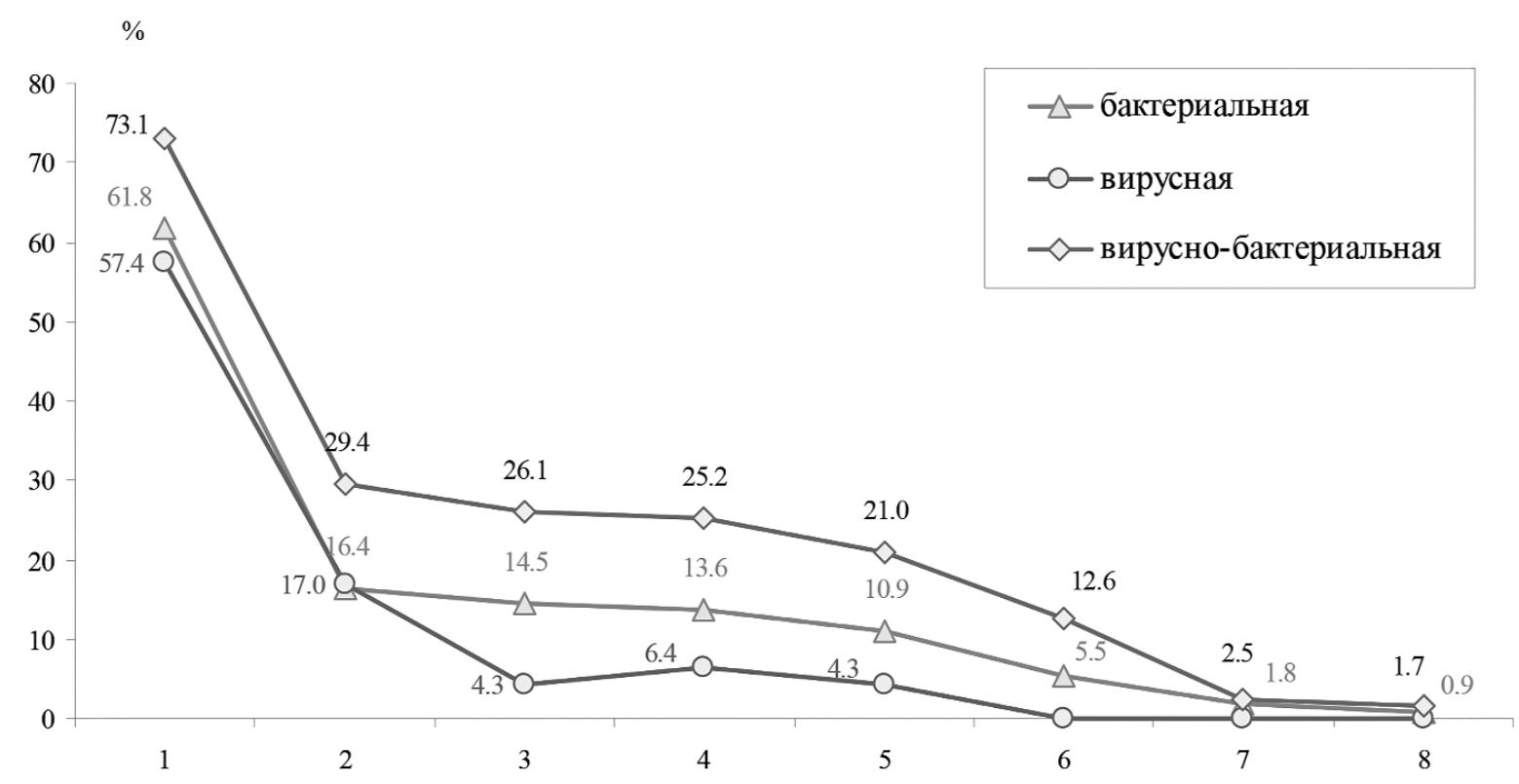

\begin{tabular}{|l|l|l|l|}
\hline 1 & эксикоз & 5 & Нейротоксикоз \\
\hline 2 & судорожный & 6 & инфекцион.токсическ.шок \\
\hline 3 & $\begin{array}{l}\text { сердечно-сосудистая } \\
\text { недостаточность }\end{array}$ & 7 & ГУС \\
\hline 4 & дыхательная недостаточность & 8 & ОПН \\
\hline
\end{tabular}

Рис. Частота основных синдромов у детей раннего возраста с неотложными состояниями при ОКИ различной этиологии 
Из рисунка видно, что при всех кишечных инфекциях в остром периоде заболевания среди всех синдромов наиболее часто встречался эксикоз различной степени, особенно в сочетании с вирусом. Сочетание патогенных и условно-патогенных бактерий с вирусом усугубляли тяжесть состояния. В развитии токсического состояния определенная роль отводилась типу возбудителя, его ассоциированной форме, преморбидным состояниям, характеру вскармливания, сопутствующим заболеваниям, состоянию иммунной системы и возрасту детей. Сравнительный анализ показателей данного синдрома у больных при ОКИ различной этиологии, показал достоверные различия между бактериальной и бактериально-вирусной $(\mathrm{p}<0.05)$ и между вирусной и бактериально-вирусной $(\mathrm{p}<0.05)$ кишечной инфекцией. Существенное значение имел возраст больного в раннем возрасте поражение желудочно-кишечного тракта более обширно, так как организм ребенка не способен локализовать патологический процесс. Именно поэтому у детей до года велик риск возникновения тяжелых, генерализованных форм ОКИ, в связи, с чем у наблюдаемых нами больных развились нарушения всех видов обмена веществ, особенно водно-солевого обмена, клинически проявляющегося синдромом эксикоза. В 51,64\% (110) случаях эксикоз являлся основным синдромом, в остальных случаях он сочетался с другими синдромами.

У детей раннего возраста при ОКИ с неотложными состояниями в структуре синдромов 2-е место занимал судорожный синдром у $21,59 \%$. Наиболее частой причиной появления судорог при инфекционной патологии у детей раннего возраста является энцефалическая реакция и нейротоксикоз. Большинство исследователей указывают на повышенную судорожную готовность детей младшего возраста, связанную с недостаточной миелинизацией проводящих путей и незрелостью тормозных механизмов коры головного мозга. Высокая частота развития судорог объясняется низким порогом возбудимости центральной нервной системы (ЦНС), склонностью к диффузным реакциям в силу морфологической и функциональной незрелости мозговой ткани, высокой гидрофильностью и сосудистой проницаемостью мозга, что способствует быстрому развитию его отека.

При бактериально-вирусной кишечной инфекции в 29,4\% ( $<0,05)$, случаях наблюдался судорожный синдром, у 13,97\% из них судороги носили тонико-клонический и клонический характер. Развитие судорожного синдрома у этих детей объяснялись следующими причинами: различные поражения ЦНС, гипокальциемия, гипогликемия, травмы головного мозга. Продолжительность судорожного синдрома составила в среднем 2,0土0,3 дня.

В структуре синдромов среди наблюдаемых больных у 51 (15,08\%) отмечалась острая дыхательная недостаточность, при этом наибольший процент был у больных с бактериально-вирусной этиологией - $31(26,1 \%)$ и $16(14,5 \%)$ - с бактериальной. Острая сердечно сосудистая недостаточность имела место у 54 больных (15,97\%), опять-таки с преобладанием бактериальновирусной $(25,2 \%)$ и бактериальной кишечной инфекцией $(13,6 \%)$.

Сравнительный анализ данных синдромов выявил достоверные различия между бактериальной и бактериально-вирусной $(\mathrm{p}<0,05$, $\mathrm{p}<0,02)$ и вирусной и бактериально-вирусной кишечными инфекциями ( $<<0,005$, ( $<<0,005)$.

У детей в результате нарушения дыхания развившаяся острая дыхательная недостаточность не компенсировалась максимальным напряжением сил и организм не был в состоянии обеспечить нормальный газообмен, который связан с анатомо-физиологическими и иммунологическими особенностями. На начальных этапах развития это состояние быстро привело к компенсаторной гипервентиляции, что клинически сопровождалось одышкой, пероральным цианозом, серовато-бледными кожными покровами, возбуждением ЦНС. Перкуторно определялось укорочение легочного звука ниже угла лопатки, аускультативно - с обеих сторон сухие и влажные крепитирующие хрипы. Этот синдром сохранялся в среднем 3-4 дня и у половины больных (50\%) усугублялся сопутствующей рентгенологически подтвержденной пневмонией.

Токсический синдром при кишечных инфекциях оказывает влияние на миокард левого 
желудочка, что является причиной развития острой сердечно сосудистой недостаточности. Клиническими симптомами были: одышка, цианоз, резкая бледность кожных покровов, тахикардия, резкое приглушение сердечных тонов и застой в малом круге кровообращения. В связи с сердечной недостаточностью нарушалась микроциркуляция, что у $1 / 3$ и проявлялось неравномерностью терморегуляции (холодные конечности при повышенной центральной температуре), бледностью кожи с мраморным рисунком, легким преходящим цианозом ногтевых фаланг. У остальных больных нарушение микроциркуляции были более выражены. Кожные симптомы варьировали от симптома «белого» пятна с нарушением тургора тканей до гипостазов с патологическим изменением тургора тканей. Продолжительность острой сердечно-сосудистой недостаточности в среднем составила 4-5 дней.

Одним из грозных синдромов при ОКИ различной этиологии у детей с неотложными состояниями был нейротоксикоз, который наблюдался у 41 (12,3\%) больного, причём, наиболее часто в возрасте до 1-года $(79,48 \%)$, что можно объясняется анатомо-физиологическими особенностями организма, а именно с незрелостью ЦНС, также с перенесенными ранее заболеваниями: асфиксия, кишечная инфекция, энцефалопатия с гипертензионным синдромом и др. В клинической картине у этих больных отмечались выбухание, напряженность и пульсация большого родничка, возбужденность, адинамия, кожная гиперестезия, судорожная готовность, судороги или наоборот помутнение сознания, переходящее косоглазие.

Нейротоксикоз - ответная, быстро прогрессирующая гиперергическая реакция организма на вирусную, бактериальную инфекцию, характеризуется очень тяжелым состоянием больного, развитием неврологических расстройств различной степени выраженности от прекомы до терминальной комы, нарушениями кровообращения, дыхания, метаболизма и водно-электролитного равновесия.

Как показывают наши клинические наблюдения, нейротоксикоз развивался у детей при ассоциации вирусно-бактериальной инфекции, являлся классическим примером токсикоза без эксикоза. Чем меньше возраст ребенка, тем больше были выражены признаки нейротоксикоза, маскирующие клинику основного заболевания.

Сравнительный анализ ОКИ с нейротоксикозом у детей с бактериальной и бактериальновирусной и вирусной с бактериально-вирусной этиологией в развитии нейротоксикоза выявил достоверную превалирующую роль бактериально-вирусной кишечной инфекции $(\mathrm{p}<0,05$, $\mathrm{p}<0,01)$. Продолжительность нейротоксикоза в среднем составила $3,0 \pm 0,3$ дня.

Инфекционно-токсический шок из 338 детей раннего возраста с неотложными состояниями при ОКИ был выявлен у 23 (6,8\%) больных: у 15 $(12,6 \%)$ с бактериально-вирусной кишечной инфекцией, у $6(5,5 \%)$ - с бактериальной и лишь 2 у больных с КИНЭ $(\mathrm{p}<0,05, \mathrm{p}<0,01)$.

Инфекционно-токсический шок возникал в результате действия микроорганизмов и их токсинов при бактериальных и вирусных кишечных инфекциях на организм ребенка. Дети с инфекционно-токсическим шоком поступали в крайне тяжелом, редко в предагональном состояниях с нарушениями микроциркуляции: холодные конечности, резкая бледность кожных покровов, с «мраморным» рисунком и цианотичностью. Отмечались рвота, диарея, возбуждение, гипертермия, снижение диуреза, одышка, тахикардия, глухость сердечных тонов. У больных при ОКИ патологические потери жидкости снижали объем циркулирующей крови, который в определенной степени компенсировал перераспределение жидкости из подкожно-жировой клетчатки в кровеносное русло. У больных с дефицитом массы тела вследствии гипотрофии, такая компенсаторная возможность существенно была ограничена, что способствовало быстрому развитию инфекционно-токсического шока.

На фоне токсического синдрома при ОКИ различной этиологии у 5 больных развился ГУС, который проявлялся гемолизом, тромбоцитопенией и ОПН. У 2 из них конечный этап токсикоза было развитие ДВС синдрома.

У некоторых больных в клинической картине заболевания отмечалось сочетание 2 или 3-х синдромов. Наиболее часто в клинической кар- 
тине ОКИ встречалось сочетание эксикоза с судорожным синдромом, несколько реже эксикоз с сердечно сосудистой недостаточностью, дыхательная недостаточность с сердечно сосудистой недостаточностью, сочетание эксикоза с дыхательной недостаточностью, сочетание сердечно сосудистой недостаточности с дыхательной недостаточностью значительно реже по сравнению эксикоза в сочетании с другими синдромами.

Из этой группы больных - 5 поступили в крайне тяжелом и предагональном состоянии с нейротоксикозом с сердечно сосудистой и 2 - с дыхательной недостаточностью, 3 - эксикоз в сочетании с сердечно сосудистой и дыхательной недостаточностью в возрасте от 2 месяцев до 1 года. Все они находились на искусственном и

\section{REFERENCES - ӘDӘBIYYYAT - ЛИTEРАTУРA}

1. Акимкин В.Г., Горелов А.В., Подколзин А.Т., Денисюк Н.Б. Эпидемиологический и молекулярно-генетический мониторинг ротавирусной инфекции в Оренбургском регионе в предвакцинальный период // Журнал микробиологии, 2019; 2: 30-36 2. Литвинчук О.А., Коновалова Т.А., Подколзин А.Т. и др. Нозокомиальные кишечные инфекции в инфекционных отделениях детских стационаров // Молекулярная диагностика, 2014; 2(12): 413-415

3. Лукъянова В.М., Бехтерева М.К., Птичникова Н.Н. Клинико-эпидемиологическая характеристика вирусных диарей у детей // Журнал инфектологии, 2014, 6 (1), с. 60-66 4. Маянский Н.А., Маянский А.Н., Куличенко Т.В. Ротавирусная инфекция: эпидемиология, патология, вакцинопрофилактика // Вестник РАМН, 2015, № 1, с.47-54.

5. Плоскирева А.А. Острые кишечные инфекции вирусной этиологии у детей: клиника, диагностика и терапия: Автореф. дисс. докт. мед. наук. М., 2016, 32 с.

6. Подколзин А.Т. Эпидемиологическая и клиническая смешанном вскармливании, у 1-го из них - развилось токсико-дистрофическое состояние. У всех этих больных наступил досуточный летальный исход.

Таким образом, причиной развития вышеуказанных синдромов у детей раннего возраста с неотложными состояниями явилась кишечная инфекция с преобладанием бактериально-вирусной этиологии. Развитию этих синдромов способствовали перенесенные ранее кишечные инфекции, затянувшаяся диарея, неоднократное лечение в амбулаторных и стационарных условиях, не рациональный и необоснованный длительный приём антибактериальных препаратов, в связи с давностью заболевания, а также ассоциация различных условно-патогенных бактерий (сальмонелл, стафилококков, протей).

характеристика острых кишечных инфекций вирусной этиологии в Российской Федерации: Автореф. дисс. докт. мед. наук. М., 2015, 31 с.

7. Lamata C., Walker C., Olaccoaga A. et al. Child Health Epidemiology reference group of the WHO and UNICEF. Global causes of diarrheal disease mortality in children $<5$ years of age // Plo S one, 2013, 8(9), p.727-88

8. Ogilvie I., Khoury H., Goetghebeur M. et al. Burden of community-acquired and nosocomial rotavirus gastroenteritis pediatric population of Western Europe // BMC Infect. Dis., 2012; 12 ; p. 62

9. Walker C., Rudan I., Liu L. et al. Global burden of childhood pneumonia and diarrhea // Lancet, 2013; 381: 1405-1416 10. Vesicari T., Hemming M., Hunti L. et al. Rotavirus antigenemia in children is associated with more severe clinical manifestations of acute gastroenteritis // Pediatr. Infect. Dis. J., 2014; 33(4): p. 366-371

11. WHO Diarrhoae, 2018

\section{XÜLASə}

\section{KəSKIN BAĞIRSAQ İNFEKSIYYASI OLAN ERKכN YAŞLI UŞAQLARDA

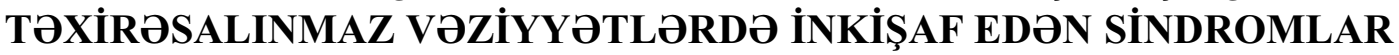

\section{${ }^{1}$ Quliyeva Z.M., ${ }^{2}$ Rüstəmova L.İ.}

`O. Oliyev adina Azərbaycan Dövlət Həkimlari Təkmillaşdirmə institutu, pediatriya kafedrası, Bakl, Azərbaycan; ${ }^{2}$ V.Y.Axundov adına Elmi-Tadqiqat Tibbi Profilaktika institutu, virusologiya şöbəsi, Bakl, Azorbaycan

Hazırkı məqalədə kəskin bağırsaq infeksiyası olan erkən yaşlı uşaqlarda təxirəsalınmaz vəziyyətlərdə inkişaf edən sindromlar təhlil edilmişdir. Təxirəsalınmaz vəziyyətdə olan 338 nəfər erkən yaşlı uşaq bakterioloji, seroloji və molekulyar-bioloji üsulla müayinə olunmuşdur.

Müəyyən edilmişdir ki, müayinə olunan pasiyentlərdə 63,0\% halda eksikoz, 21,6\% - gicolma, 15,9\% - ürək-damar çatmamazlığı, 15,0\% - tənəffüs çatmamazlığı, 12,1\% - neyrotoksikoz, 6,8\% - infeksion-toksik şok qeydə alınır. 
Bizim klinik müşahidələrə əsasən neyrotoksikoz erkən yaşlı uşaqlarda xüsusilə bakterial-virus bağırsaq infeksiyası zamanı rast gəlir. Tədqiqatların nəticələri göstərir ki, qeyd olunan sindromlar erkən yaşlı uşaqlarda təxirəsalınmaz vəziyyətlərdə əsas etibarilə bakterial-virus bağırsaq infeksiyası zamanı müşahidə olunur.

Açar sözlər: kəskin bağırsaq infeksiyası, təxirəsalınmaz vəziyyət, bakterial-virus bağırsaq infeksiyası, erkən yaşlı uşaqlar

\title{
SUMMARY
}

\section{THE SYNDROMES APPEARING IN CHILDREN OF EARLY AGE} WITH ACUTE ENTERIC INFECTIONS IN URGENT CONDITIONS

\author{
${ }^{1}$ Kuliyeva Z.M., ${ }^{2}$ Rustamova L.I. \\ ${ }^{1}$ The Azerbaijan State Advanced Training Institute for Doctors named after A.Aliyev, \\ Department of pediatry, Baku, Azerbaijan; \\ ${ }^{2}$ Scientific-Research Institute of Medical Prophylaxis named after V.Y.Akhundov, \\ Virology Department, Baku, Azerbaijan
}

The clinical syndroms developing in children of early age with acute enteric infections in urgent conditions have been analysed. 338 children of early age with urgent conditions have been observed by bacteriological, serological and molecular-biological methods. It was determined that in observing patients in $63.0 \%$ of cases the exicosis, in $21,6 \%$ - cramp, in 15,9\% - cardiovascular insufficiency, in 15,0\% - pulmonary insufficiency, in 12,1\% - neurotoxicosis, in $6,8 \%$ - infectious - toxic shock have been registrated. In accordingly to our clinic observations the neurotoxicosis appear in children of early age with urgent conditions especially in bacterial-viral enteric infection. The results of investigation show that the appearing syndroms in children of early age with urgent conditions mainly may meet in bacterial-viral enteric infection.

Keywords: acute enteric infection, the urgent condition, bacterial-viral enteric infection, children of early age.

Redaksiyaya daxil olub:

Çapa tövsiya olunub:

Rayçi: prof. A.K.Məmmadbəyli 